\title{
Factors Associated with Early Platelet Activation in Obese Children
}

\author{
Anel Gómez García, PhD; Guillermina García Núñez, MSC; Martha Eva Viveros Sandoval, PhD; \\ Sergio Gutierrez Castellanos, PhD; and Cleto Alvarez Aguilar, MSC
}

Objective: To investigate the factors associated with platelet activation in obese children.

Design: Cross-sectional study.

Setting: Department of Pediatrics of Regional Hospital $N^{\circ}$ I of Mexican Institute of Social Security in Morelia, Michoacán, Mexico.

Participants: 79 obese and 64 non-obese children between the ages of 5 and 10 years.

Main Outcomes Measures: Obese children (body mass index [BMI] >85 in growth curves for Centers for Disease Control/National Center for Health Statistics), and the control group of 64 nonobese children (percentile <85), \% body fat, platelet activation was assessed by sP-selectin. Other measures were leptin, uric acid (UA), von Willebrand Factor (VWF), plasminogen activator inhibitor (PAI-I), lipid profile, and glucose.

Results: Obese children displayed higher plasma sP-selectin, leptin, PAI-I, and VWF than non-obese children. In the univariate logistic regression analysis, leptin, vWF, UA, and high density lipoprotein (HDL), but not with PAI-I, were factors associated with platelet activation. By stepwise linear regression analysis adjusted by sex and age, the best predictor variables for platelet activation were leptin ( $\beta: 0.38 \mathrm{I} ; \mathrm{t}: 4.665 ; P=0.000 \mathrm{I})$, vWF ( $\beta: 0.2 \mathrm{I} \mathrm{I} ; \mathrm{t}: 2.926 ; P=0.004), \mathrm{UA}(\beta: 0.166 ; \mathrm{t}: 2$. I $46 ; P=0.034)$, and HDL ( $\beta:-0.215$; t:-2.8I9; $P=0.006)$.

Conclusions: Obese children have a higher risk of developing early platelet activation. Factors associated with platelet activation were Leptin, vWF, UA, and HDL. Further studies involving larger numbers of patients over a longer duration are needed to understand the possible molecular mechanism underlying the association between leptin, vWF, and UA and endothelial activation and/or endothelial damage/dysfunction in obese children and its influence in cardiovascular disease in adults.

Keywords: Children; Endothelial activation; Leptin; Obesity; Uric acid

$\mathrm{C}$ hildhood obesity is a public health problem in Mexico and worldwide because of the later clinical consequences including diabetes mellitus, hypertension, and cardiovascular disease (CVD). ${ }^{1}$ The rapid increase in the prevalence and severity of obesity in children likely lowers the age of onset and increases the incidence of CVD. Childhood obesity is associated with endothelial dysfunction, one of the earliest changes in the development of atherosclerosis, ${ }^{2,3}$ and evidence supports atherosclerotic cardiovascular disease beginning in childhood. ${ }^{4}$ Additionally, the high serum levels of low density lipoprotein (LDL)-cholesterol and total cholesterol in childhood were associated in adults with carotid intima-media thickness ${ }^{5}$ and subclinical atherosclerosis. ${ }^{6}$ In adults, inflammation, endothelial dysfunction, and hyperuricemia are factors that contribute to a link between obesity and CVD. Leptin has been shown to 
Table 1. Clinical and biochemical variables of obese and non-obese children.

\begin{tabular}{|c|c|c|c|}
\hline Variables & $\begin{array}{l}\text { Obese } \\
n=79\end{array}$ & $\begin{array}{c}\text { Non-obese } \\
n=64\end{array}$ & $P$ value \\
\hline Age, yr & $7.44 \pm 1.44$ & $7.20 \pm 1.26$ & 0.411 \\
\hline Male/female, $\mathrm{n}$ & $50 / 29$ & $37 / 27$ & \\
\hline $\mathrm{BMI}, \mathrm{kg} / \mathrm{m}^{2}$ & $21.77 \pm 2.84$ & $15.83 \pm 0.96$ & 0.0001 \\
\hline Body fat content, \% & $31.56 \pm 6.37$ & $18.06 \pm 3.61$ & 0.0001 \\
\hline Body surface area, $\mathrm{m}^{2}$ & $1.22 \pm 0.25$ & $0.91 \pm 0.12$ & 0.0001 \\
\hline $\mathrm{sBP}, \mathrm{mmHg}$ & $96.64 \pm 9.42$ & $88.67 \pm 7.35$ & 0.0001 \\
\hline $\mathrm{dBP}, \mathrm{mmHg}$ & $58.03 \pm 8.29$ & $51.40 \pm 4.91$ & 0.0001 \\
\hline Hemoglobin, g/dL & $14.71 \pm 0.74$ & $14.20 \pm 0.85$ & 0.019 \\
\hline Platelets, $\times 10^{3}$ cells $/ \mu \mathrm{L}$ & $362.35 \pm 71.15$ & $326.79 \pm 55.27$ & 0.014 \\
\hline Glucose, mg/dL & $88.97 \pm 6.23$ & $87.60 \pm 6.48$ & 0.203 \\
\hline Uric Acid, mg/dL & $4.51 \pm 0.95$ & $3.81 \pm 0.78$ & 0.0001 \\
\hline Total Cholesterol, mg/dL & $170.64 \pm 28.58$ & $165.97 \pm 31.74$ & 0.357 \\
\hline Triglycerides, mg/dL & $115.48 \pm 57.12$ & $77.11 \pm 27.81$ & 0.0001 \\
\hline $\mathrm{HDL}, \mathrm{mg} / \mathrm{dL}$ & $44.66 \pm 10.62$ & $50.95 \pm 10.31$ & 0.001 \\
\hline LDL, mg/dL & $102.59 \pm 25.81$ & $100.51 \pm 29.84$ & 0.655 \\
\hline Leptin , pg/mL & $26.77 \pm 10.66$ & $14.35 \pm 4.18$ & 0.0001 \\
\hline PAI-1, pg/mL & $64.18 \pm 30.49$ & $43.24 \pm 18.06$ & 0.0001 \\
\hline $\mathrm{vWF}, \mathrm{U} / \mathrm{mL}$ & $93.19 \pm 9.70$ & $83.55 \pm 11.57$ & 0.0001 \\
\hline sP-Selectin, ng/mL & $45.65 \pm 9.01$ & $29.39 \pm 6.40$ & 0.0001 \\
\hline
\end{tabular}

Data are expressed as mean \pm SD. BMI, Body mass index; SBP, systolic blood pressure; dBP, diastolic blood pressure; HDL, high density lipoproteins; LDL, low density lipoproteins; PAI-1, Plasminogen activator inhibitor-1; vWF, von Willebrand Factor.

$t$-Student test $P<0.05$

represent an important candidate linking these disorders, ${ }^{7,8}$ because of the potential role in the regulated functioning of the immune system, ${ }^{9}$ on platelet activation and segregation, ${ }^{10}$ and on relation with uric acid (UA). ${ }^{11}$

In the presence of obesity, inflammation leads to platelet activation and increased plasma levels of prothrombotic proteins stored in platelet $\alpha$-granules including soluble P-selectin (sP-selectin), von Willebrand Factor (vWF), and plasminogen activator inhibitor-1 (PAI-1). High levels of these proteins are believed to play a central role in accelerating the risk of atherothrombosis. ${ }^{12}$ sP-selectin is not only expressed on activated endothelial cells, but also on activated platelets, and it mediates rosetting of the platelets with monocytes and neutrophils that contribute to atherosclerotic lesion. ${ }^{13}$ It is, therefore, considered a plasma marker of platelet activation and endothelial dysfunction in the atherogenic process that has been related to adverse cardiovascular events in adults. ${ }^{14,15} \mathrm{vWF}$ levels have been significantly associated with insulin resistance (IR). ${ }^{16}$ Increased PAI-1 levels have been associated with the risk of thrombosis and fibrosis, and it has been shown to have a direct effect in the development of IR and type 2 diabetes. ${ }^{17}$

Disorders of UA metabolism are often seen in conjunction with factors associated with lifestyles such as an unbalanced diet abundant in purine, obesity, and alcohol consumption. ${ }^{18}$ In adolescents, UA levels are significantly increased with obesity, ${ }^{19}$ and some studies suggests that UA stimulates vascular inflammation and endothelial dysfunction, and it predicts adult blood pressure..$^{20-22}$ The aim of our study was to investigate the factors associated with platelet activation in obese children.

\section{Methods}

Participants

Between March 2009 and February 2010, a cross-sectional study was carried out in 143 children of both sexes from whom demographic and clinical data were collected. At the time of the study, the children were between the ages of 5 and 10 years. One group consisted of 79 obese children (body mass index [BMI] over percentile 85 in growth curves for Centers for Disease Control/National Center for Health Statistics), and the other (control group) consisted of 64 nonobese children (percentile $<85$ ). Children were consecutively enrolled at the Department of Pediatrics of Regional Hospital $\mathrm{N}^{\circ} 1$ of Mexican Institute of Social Security in Morelia, Michoacán, Mexico. Children with primary hyperlipidemia, hypertension, diabetes, or glucose intolerance were excluded from both the test group and the control group, as were children with secondary obesity. Any child receiving pharmacological treatment was also excluded. The study was authorized by the Hospital Ethical Research Committee. All parents gave their written consent, and children gave their verbal and written assent.

Anthropometric Measurements and Blood Pressure Weight was measured to the nearest $0.1 \mathrm{~kg}$ and height to the 

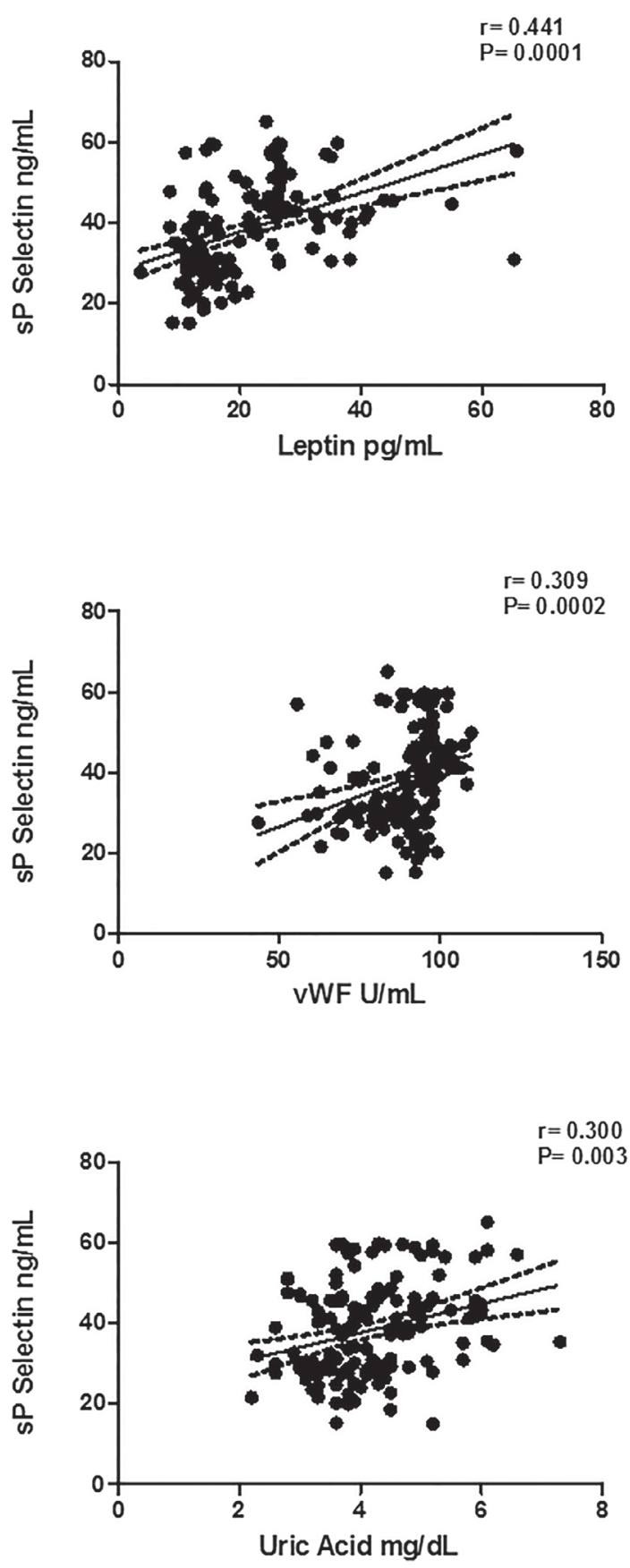

Figure 1. Univariate correlations between sP-selectin and leptin, vWF (von Willebrand Factor), and uric acid in obese children.

nearest $0.1 \mathrm{~cm}$. BMI was calculated as weight $(\mathrm{kg}) / \mathrm{height}$ $\left(\mathrm{m}^{2}\right)$; percentage body fat was assessed by bioelectrical impedance ${ }^{23}$ and body surface area (BSA) was calculated with Haycock formula. ${ }^{24}$ Blood pressure was measured with a mercury sphygmomanometer after 20 minutes rest, in a supine position. Three sizes of cuff were used $(9 \times 21,11 \times 36$, and $12 \times 41 \mathrm{~cm}$ ); the cuff width was required to cover twothirds of the length of the child's arm.

Blood Sampling

Blood samples of all children were collected after 12 hours fasting from a vein in the antecubital fossa, without venous occlusion. Before collecting the blood, we asked parents of each child the hour of last food for fasting confirmation. Blood samples were separated into aliquots and frozen immediately at $-70^{\circ} \mathrm{C}$ until analysis to avoid interassay variability.

Glucose, UA, cholesterol, triglycerides (TG), and high density lipoprotein (HDL), and LDL concentrations were measured using an automatic analyzer (Roche Diagnostics, Mannheim, Germany). Blood count was determined by hematologic analyzer (Nihon Kohdem Corporation, Japan). Leptin and sP-selectin were determined by an enzyme immunoassay (Invitrogen Corporation, CA, USA). vWF:Ag was determined by enzyme-linked immunosorbent assay (ELISA) (Immubind, American Diagnostica, USA). PAI-1 was determined by ELISA (Prepro-Tech Inc, USA). In all determinations, the intra- and interassay variability was $<5 \%$. A value of sP-selectin $\geq 44.32 \mathrm{ng} / \mathrm{mL}$ (third quartile) was the cut-off point considered for analyzing platelet activation.

\section{Statistical Analysis}

Data were stored and analyzed using SPSS 18.0 statistical package (SPSS Inc, Chicago, IL). Test selection was based on evaluating the variables for normal distribution using the Kolmogorov-Smirnov test. Differences between groups were calculated using a Student's t-test for independent samples. Pearson's correlation and linear regression coefficients were used to analyze the relation between variables. The independence of association of leptin with platelet activation was assessed by logistic regression analysis (when dependent variable, ie. platelet activation [sP-selectin] was entered as a categorical variable stratifying into two groups according to the 75 th percentile observed $(44.32 \mathrm{ng} / \mathrm{mL})$.

Univariate linear regression analyses and stepwise regression models were used to test the predictive association of biochemical parameters (Leptin, PAI-1, vWF, UA, glucose, cholesterol, triglycerides, LDL, HDL, and PAI-1) with platelet activation. A $P<0.05$ was considered statistically significant in all cases.

\section{Results}

Demographic, clinical, and biochemical characteristics of all participants in the study are presented in table 1. Obese children displayed higher plasma concentrations of sP-selectin, leptin, PAI-1, vWF and serum UA levels than non-obese children. Similarly, obese children had higher values of systolic and diastolic blood pressure than non-obese children. Correlations of leptin, vWF, and UA with platelet activation (sP-selectin) are shown in figure 1. Correlations between BMI, percent body fat, and BSA with sP-selectin are shown in figure 2. Subsequently, leptin levels correlated positively with BMI $(\mathrm{r}=0.535 ; P=0.0001)$, percent body fat content $(\mathrm{r}=0.541 ; P=0.0001)$, triglycerides $(\mathrm{r}=0.317 ; P=0.0001)$, UA $(\mathrm{r}=0.343 ; P=0.0001)$, and negatively with HDL $(\mathrm{r}=-0.211$; $P=0.011$ ). 

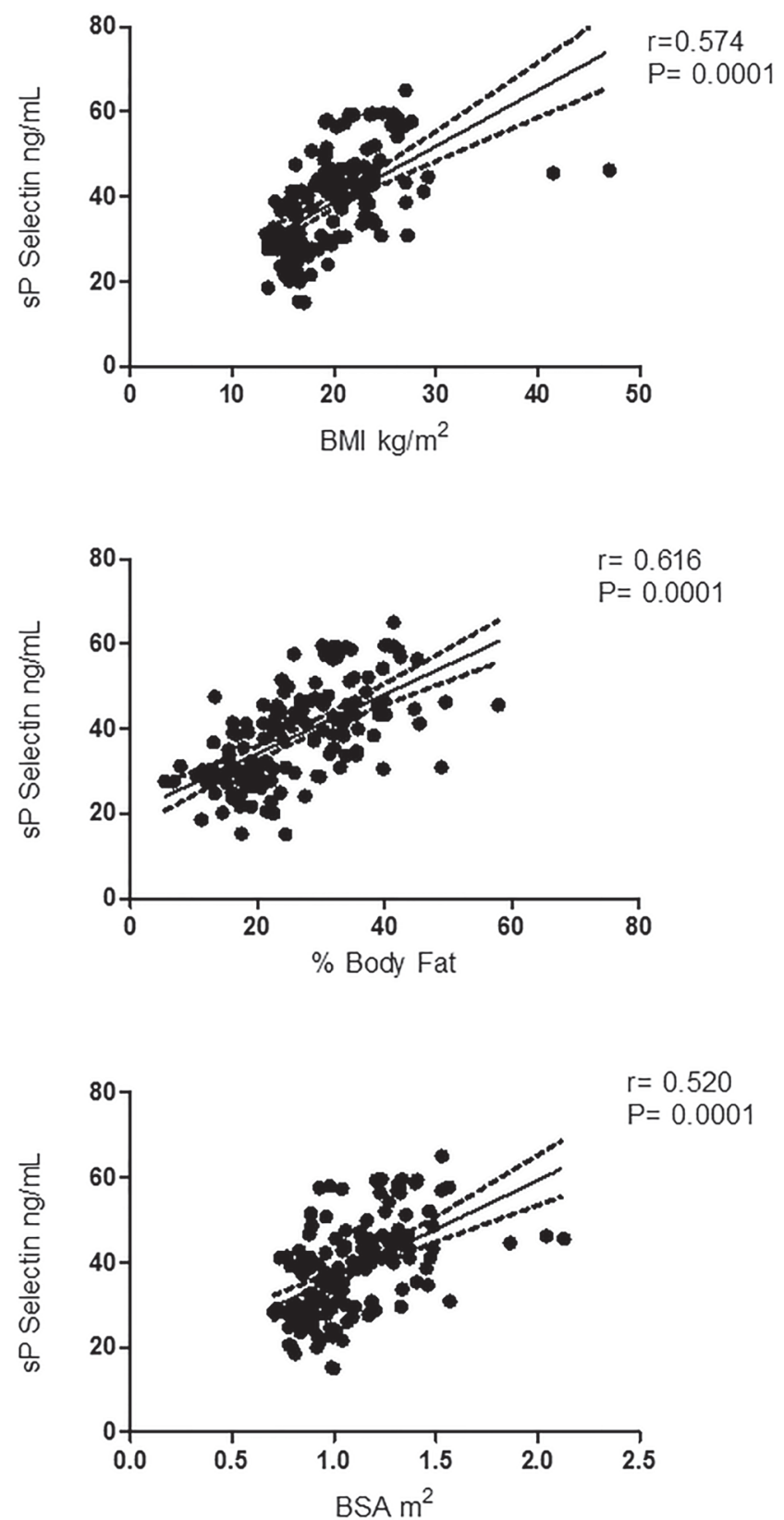

Figure 2. Univariate correlations between sP-selectin and body mass index (BMI), \% body fat, and body surface area (BSA) in obese children.

In the stepwise linear regression analysis, the best predictor variables for platelet activation were leptin ( $\beta: 0.395$; IC95\% $0.229-0.561 ; \mathrm{t}: 4.697 ; P=0.0001)$, vWF $(\beta: 0.211 ; \mathrm{IC} 95 \%$ $0.148-0.441 ; \mathrm{t}: 2.926 ; P=0.004), \mathrm{UA}(\beta: 0.208 ;$ IC95\% 0.129$0.561 ; \mathrm{t}: 2.477 ; P=0.014)$, and HDL $(\beta:-0.215$; IC95\% $-0.402-$ $0.561 ;$ t:-2.819; $P=0.006)$. Serum glucose, cholesterol, LDL, body fat, and waist circumference were non-predictor variables for platelet activation.

Finally, figure 3 shows the relative risk and its $95 \%$ confidence interval adjusted by sex and age. Leptin, vWF, UA, and HDL, but not with PAI-1, were risk factors associated with platelet activation.

\section{Discussion}

The results of this study support that high circulating levels of sP-selectin, leptin, PAI-1, vWF, and UA in childhood obesity are related to the presence of platelet activation and may promote early vascular abnormalities potentially responsible for increased cardiovascular morbidity and mortality later in life. In addition, adipose tissue accumulation probably represents the main risk factor responsible for platelet size, activation of vascular endothelium, and release of prothrombotic proteins in obese children. ${ }^{25}$ Notably, leptin, $\mathrm{vWF}$, and UA were independent risk factors in platelet activation.

The involvement of leptin in increased platelet activation in human obesity is not universally accepted, since several studies $^{25-27}$ provided conflicting results about platelet responsiveness to leptin in overweight and obesity in adults. Like Fochini et $a l,{ }^{10}$ we confirm that obese children have higher leptin and platelet concentrations compared with nonobese children, so this increase could favor early functional alterations and represent higher risk for developing early atherosclerosis and CVD. A possible mechanism can be related to adenosine concentration (ADO) as an endogenous mediator released from platelets storage granules. ${ }^{28}$ In vitro studies showed that Leptin synergizes with subthreshold concentrations of agonists such as ADO to induce platelet aggregation. ${ }^{29}$ In this context, Elbatarny and Maurice ${ }^{30}$ reported that leptin-induced platelet activation via activation of PDE3A may represent a molecular basis for the association between hyperleptinemia and cardiovascular disease. However, more studies are needed to confirm this molecular mechanism in children.

In adults, obesity is associated with higher levels of circulating endothelial dysfunction biomarkers such SICAM-1 and vWF. ${ }^{31}$ In our study, soluble intercellular adhesion molecule-1 (sICAM-1) was not quantified, but vWF was higher in obese children. We found an association between vWF and sP-selectin. However, it is reasonable to assume the probability of early endothelial damage additionally to platelet activation and proinflammatory effect of leptin in obese children.

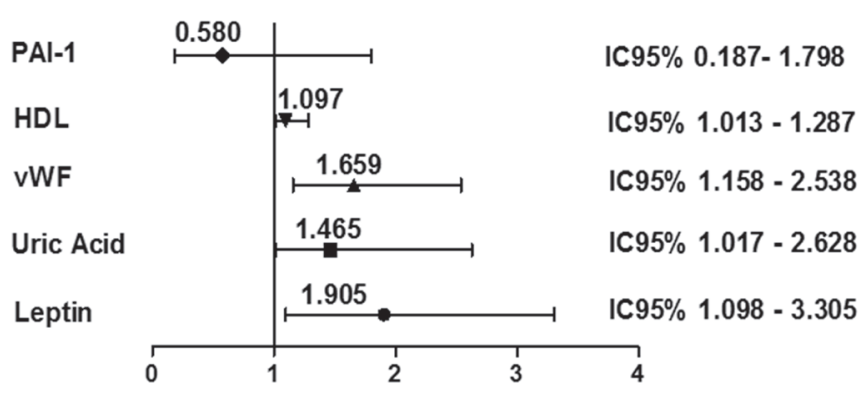

Figure 3. Relative risk analysis between platelet activation (sP-selectin, as dependent variable) and leptin, vWF, PAl-1, uric acid and HDL in obese children (PAl-1: Plasminogen activator inhibitor-1; vWF: von Willebrand Factor; HDL: High density lipoproteins). 
Equally important, we found an association between UA and sP-selectin. The relationship between UA and endothelial activation (sP-selectin) is consistent with the pro-oxidative effect and proatherogenic properties of UA, including endothelial cell activation, platelet activation, and increased platelet adhesiveness. ${ }^{32}$ The role of UA as an additional risk factor for developing endothelial dysfunction and smooth muscle cell proliferation is caused by an excessive activity of xanthine oxidase enzyme by degraded purine metabolism and formation of reactive oxygen and nitrogen species that lead to oxidative stress and later to development of endothelial dysfunction. ${ }^{33}$

Bedir et $\mathrm{al}^{11}$ showed that serum leptin level was independently associated with UA only in overweight and obese adults. Our results about the correlation between leptin and UA in obese children are consistent with the theory by Bedir that leptin appears to be a good candidate for the missing link between obesity and hyperuricemia.

In this study, triglycerides and HDL were higher in obese children, but only HDL was a predictor factor by platelet activation. The Bogalusa study ${ }^{34}$ showed that in overweight 5- to 10-year-old children had two or more cardiovascular risks factors (hypertriglyceridemia, high LDL, and low HDL) that would substantially increase the risk for earlier cardiovascular disease. Likewise, we and others have recently reported that low levels of HDL are associated with metabolic syndrome and cardiovascular risk in Mexican children. ${ }^{35-37}$ To our knowledge, this is the first report of early platelet activation in Mexican obese children. Finally, we found in this study that obese children had higher blood pressure values than non-obese children; hence, a higher blood pressure could induce endothelial activation. Obesity and high blood pressure are suggested as risks factor for early development of hypertension in this population. In fact, we previously reported this in children of parents with diabetes mellitus or arterial hypertension. ${ }^{35}$

This study has some limitations. First, the study is of a crosssectional nature, and in the absence of a prospective longitudinal analysis, interpretation of the correlations can only be inferred. Second, the information about lifestyles of the children is limited. The habit of frequently consuming purine-rich foods or fruit juices may cause increased leptin and UA levels. Intake of carbohydrates, lipids, and proteins in the Mexican diet, along with portion sizes, and frequency of intake should be evaluated in obese children.

\section{Conclusion}

In obese children who presented with early presence of platelet activation, leptin, vWF, UA, and HDL were factors associated with the platelet activation. In medical practice, we need to do early detection of risk factors for CVD in children. Further studies involving larger numbers of patients over a longer duration are needed to understand the possible clinical and molecular mechanisms underlying the association between leptin, vWF, and UA and endothelial activation and/ or endothelial damage/dysfunction in obese children and its implications in CVD in adulthood.

\section{References}

1. Slyper AH. The pediatric obesity epidemic: causes and controversies. J Clin Endocrinol Metab 2004;89:2540-2547.

2. Vanhoutte PM. Endothelial dysfunction: first step towards coronary disease. Circulation J 2009;73:595-601.

3. Falaschetti E, Hingorani AD, Jones A, Charakida M, Finer N, Whincup P, Lawlor DA, Davey Smith G, Sattar N, Deanfield JE. Adiposity and cardiovascular risk factors in a large contemporary population of pre-pubertal children. Eur Heart J 2010;31:3063-3072.

4. Hong YM. Atherosclerotic cardiovascular disease beginning in childhood. Korean Circ J 2010;40:1-9.

5. Li S, Chen W, Srinivasan SR, Berenson GS. Childhood cardiovascular risk factors and carotid vascular risk changes in adulthood: the Bogalusa Heart Study. JAMA 2003;290:2271-2276.

6. Frontini MG, Srinivasan SR, Xu J, Bond MG, Berenson GS. Usefulness of childhood non-high density lipoprotein cholesterol levels versus other lipoprotein measures in: the Bogalusa Heart Study Maria G. Pediatrics 2008;121; 924-929.

7. Werner N, Nickenig G. From fat fighter to risk factor: the zigzag trek of leptin. Arterioscler Thromb Vasc Biol 2004;24:7-9.

8. Sader S, Nian M, Liu P. Leptin: a novel link between obesity, diabetes, cardiovascular risk, and ventricular hypertrophy. Circulation 2003;108:644-646.

9. Fantuzzi G, Faggioni R. Leptin in the regulation of immunity, inflammation, and hematopoiesis. J Leukoc Biol 2000;68:437-446.

10. Foschini D, dos Santos RVT, Prado WL, de Piano A, Lofrano MC, Martins AC, Carnier J, Caranti DA, Sanches Pde L, Tock L, Mello MT, Tufik S, Samaso AR. Platelet and leptin in obese adolescents. J Pediatr (Rio J) 2008;84:516-521.

11. Bedir A, Topbas M, Tanyeri F, Alvur M, Arik N. Leptin might be a regulator of serum uric acid concentrations in humans. Jpn Heart J 2003;44:527-536.

12. Coban E, Ozdogan M, Yazicioglu G, Akcit F. The mean platelet volume in patients with obesity. Int J Clin Pract 2005;59:981-982.

13. Burger PC, Wagner DD. Platelet P-selectin facilitates atherosclerotic lesion development. Blood 2003;101: 2661-2666.

14. Blann AD, Faragher EB, McCollum CN. Increased soluble P-selectin following myocardial infarction: a new marker for the progression of atherosclerosis. Blood Coagul Fibrinolysis 1997;8:383-390.

15. Ridker PM Buring JE, Rifai N. Soluble P-selectin and the risk of future cardiovascular events. Circulation 2001;103: 491-495.

16. Valle Jiménez M, Martos Estepa R, Morales Camacho RM, Cañete Estrada R, Gascón Luna F, Bermudo Guitarte F. Endothelial dysfunction is related to insulin resistance and inflammatory biomarker levels in obese prepubertal children. European J Endocrinol 2007:156:497-502.

17. Ford ES, Li C, Cook S, Choi HK. Serum concentrations of uric acid and the metabolic syndrome among US children and adolescents. Circulation 2007;115:2526-2532.

18. Nakanishi N, Yoshida H, Nakamura K, Suzuki K, Tatara K. Predictors for development of hyperuricemia: an 8-year longitudinal study in middle-aged Japanese men. Metabolism 2001;50:621-626.

19. Oyama Ch, Takahashi T, Oyamada M, Oyamada T, Ohno T, Miyashita M, Saito S, Komatsu K, Takashina K, Takada G. Serum uric acid as an obesity-related indicator in early adolescence. Tohoku J Exp Med 2006;209:257-262. 
20. Kanellis J, Kang DH. Uric acid as a mediator of endothelial dysfunction, inflammation, and vascular disease. Semin Nephrol 2005;25:39-42.

21. Ishizaka N, Ishizaka Y, Toda E, Hashimoto H, Nagai R, Yamakado M. Higher serum uric acid is associated with increased arterial stiffness in Japanese individuals. Atherosclerosis 2007;192:131-137.

22. Alper AB, Lillian Yau WC, Srinivasan SR, Berenson GS, Lee Hamm L. Childhood uric acid predicts adult blood pressure: the Bigalusa Heart Study. Hypertension 2005;45:34-38.

23. Sánchez Jaeger A, Barón MA. Uso de la bioimpedancia eléctrica para la estimación de la composición corporal en niños y adolescentes. An Venez Nutr 2009;22:105-110.

24. Haycock GB, Schwartz GJ, Wisolsky DH. Geometric method for measuring body surface area: a height-weight formula validated in infants, children and adults. J. Pediatr 1978;93:62-66.

25. Prabhakaran B, Ferranti SD, Cook S, Daniels SR, Gidding SS, Hayman LL, McCrindle BW, Mietus-Snyder, Steinberg J; American Heart Association Committee on Atherosclerosis Hypertension and Obesity in Youth of the Council on Cardiovascular Disease in the Young; Council on Nutrition, Physical Activity and Metabolism; Council on Epidemiology and Prevention. Nontraditional Risk Factors and Biomarkers for Cardiovascular Disease: Mechanistic, Research, and Clinical Considerations for Youth: A scientific statement from the American Heart Association. Circulation 2011;123:3254-3256.

26. Konstantinides S, Schäfer K, Koschnick S, Loskutoff DJ. Leptin-dependent platelet aggregation and arterial thrombosis suggests a mechanism for atherothrombotic disease in obesity. J Clin Invest 2001;108:1533-1540.

27. Dellas C, Schäfer K, Rohm I, Lankeit M, Ellrott T, Faustin V, Riggert J, Hasenfuss G, Konstantinides S. Absence of leptin resistance in platelets from morbidly obese individuals may contribute to the increased thrombosis risk in obesity. Thromb Haemost 2008;100:1123-1129.

28. Rivera J, Lozano ML, Navarro-Núñez L, Vicente V. Platelet receptors and signaling in the dynamics of thrombus formation. Haematologica 2009;94:700-711.

29. Corsonello A, Perticone F, Malara A, De Domenico D, Loddo S, Buemi M, Ientile R, Corica F. Leptin-dependent platelet aggregation in healthy, overweight and obese subjects. Int J Obes Relat Metab Disord 2003;27:566-573.

30. Elbatarny HS, Maurice DH. Leptin-mediated activation of human platelets: involvement of a leptin receptor and phosphodiesterase 3A-containing cellular signaling complex. Am J Physiol Endocrinol Metab 2005;289:E695-E702.

31. Weyer C, Yudkin JS, Stehouwer CD, Schalkwijk CG, Pratley RE, Tataranni PA. Humoral markers of inflammation and endothelial dysfunction in relation to adiposity and in vivo insulin action in Pima Indians. Atherosclerosis 2002;161:233-242.

32. Krzystek-Korpacka M, Patryn E, Kustrzeba-Wojcicka I, Chrzanowska J, Gamian A, Noczynska A. Gender-specific association of serum uric acid with metabolic syndrome and its components in juvenile obesity. Clin Chem Lab Med 2011;49:129-136.

33. Feig DI, Kang DH, Johjsin RJ. Uric acid and cardiovascular risk. N Engl J Med 2008;359:1811-1821.

34. Freedman DS, Dietz WH, Srinivasan SR, Berenson GS. The relation of overweight to cardiovascular risk factors among children and adolescents: the Bogalusa Heart Study. Pediatrics 1999;103:1175-1182.

35. Gómez-García A, Rangel-García L, Alvarez-Aguilar C. [A cross-sectional study to assess cardiovascular risk in the children of parents with diabetes mellitus or arterial hypertension]. [Article in Spanish] Semergen 2012;38: 278-284.
36. Klünder-Klünder M, Flores-Huerta S, García-Macedo R, Peralta-Romero J, Cruz M. Adiponectin in eutrophic and obese children as a biomarker to predict metabolic syndrome and each of its components. BMC Public Health 2013;13:88.

37. Grundy SM, Brewer HB Jr, Cleeman JI, Smith SC Jr, Lenfant C; National Heart, Lung, and Blood Institute; American Heart Association. Definition of metabolic syndrome: report of the National Heart, Lung, and Blood Institute/American Heart Association conference on scientific issues related to definition. Circulation 2004;109:433-438.

\section{Author Affiliations}

Anel Gómez García, PhD*; Guillermina García Núñez, $\mathrm{MSc}^{*}$; Martha Eva Viveros Sandoval, PhD"; Sergio Gutierrez Castellanos, $\mathrm{PhD}^{\S}$; and Cleto Alvarez Aguilar, $M S c^{\S}$

\author{
"Biomedical Research Center of Michoacán, Mexican \\ Institute of Social Security, Morelia, Michoacán, México. \\ 'Department of Pediatrics, Mexican Institute of Social \\ Security, Morelia, Michoacán, Mexico. \\ *Postgrade of Medicine Faculty "Dr Ignacio Chávez" \\ Universidad Michoacana de San Nicolás de Hidalgo, \\ Morelia, Michoacán, Mexico. \\ ${ }^{\S}$ Regional General Hospital $N^{\circ} 1$, Mexican Institute of Social \\ Security, Morelia, Michoacán, Mexico.
}

